\title{
Blogging a Personal Window to Pleasure and Self-therapy: A Case Study of Iranian Women Bloggers
}

\author{
Ayoub Zareie ${ }^{1} \&$ Nor Hafizah Selamat ${ }^{1,2}$ \\ ${ }^{1}$ Department of Anthropology and sociology, School of Social Sciences, Universiti Sains Malaysia, Penang, \\ Malaysia \\ ${ }^{2}$ Women's Development Research Centre (KANITA), Universiti Sains Malaysia, Penang, Malaysia \\ Correspondence: Ayoub Zareie, School of Social Sciences, Universiti Sains Malaysia, 11800, Penang, Malaysia. \\ Tel: 60-17-448-5294. E-mail:ubi.zarei@gmail.com
}

Received: March 26, 2014 Accepted: June 11, 2014 Online Published: July 11, 2014

doi:10.5539/ass.v10n15p16

URL: http://dx.doi.org/10.5539/ass.v10n15p16

\begin{abstract}
New media have made a broad and immense change in our contemporary society. Proliferation of new media in recent decade has provided a great deal of opportunity for people. This study intended to scrutinise the meaning of blogging among the Iranian women bloggers. By applying Interpretative Phenomenological Analysis (IPA) as a research strategy, 11 Iranian women bloggers were selected for in-depth interviews. The findings of the study show that different bloggers gave different meaning to their blogging activities. Majority of them view blogging as their personal window to experience pleasure and self-therapy. Blogging has become a personal window for the bloggers to express their feelings, ideas and opinions despite the restrictions that they experienced in the 'outside' world. Blogging gave a voice to the bloggers to express their opinions and a chance to be heard. For majority of them, blogging is also a medium to release their stress and worries.
\end{abstract}

Keywords: blogging, interpretive phenomenological analysis, Iranian women bloggers, Iran

\section{Introduction}

To me, blogging grew steadily. Gradually, it became what it is today. During the first days, it was just an excuse to write. It was something to fill my friends' empty place. Later, I saw there were many people around me. I finally found a place to 'say' my words. There are many people who visit the blog, read and left. Sometimes, they leave a trace but many times quietly passing by. But I see them. The pleasure of being read, the pleasure of writing and the freedom of writing whatever that I want to, the pleasure of having my own window for 'shouting' all comes to me little by little (Negar, 36).

New media have made a broad and immense change in our contemporary society. Proliferation of new media in recent decade has provided a great deal of opportunity for people. Currently, some 2 billion people are estimated to be internet users across the globe, sharing around $34.3 \%$ of the world population (Note 1). According to Nardi, Schiano, and Gumbrecht (2004), weblog or blog is referring to "a frequently updated web page with a series of archived posts, typically in reverse-chronological order" (p. 1), whereas blogosphere refers to personal websites and blogs collectively. Weblogs are reported to have begun in 1997 and continue to increase ever since. By the end of 2011, there were over 176 million public blogs operating in the world (Note 2). Iran has been one of the countries witnessing a rapid proliferation of internet users. The country is acknowledged to have at least 250,000 internet users in 2000 and 33.2 million in 2011 (Note 1). 'Weblogistan' is known to be one of the largest and most active blogospheres in the world (Sifry, 2007). Weblogistan or the Persian blogosphere refers to "the collectivity of weblogs on the Internet but often connotes specifically the Persian-language blogging community" (Doostdar, 2004, p. 660).

Although it was hard to document the exact figures of blogger population in Iran (Amir-Ebrahimi, 2009), it was often acknowledged that the active blogs stood at virtually 60,000 (Kelly \& Etling, 2008). However, this number is remained uncorroborated since some studies continued to challenge this number (Hendelman-Baavur, 2007; Sreberny \& Khiabany, 2010). Out of this number, some $40 \%$ of them were women (Halavi, 2006). The advent of weblog writing in Iran dated back to September 2001 (Amir-Ebrahimi, 2008a). Not long after that, three young educated women launched their own blogs in November 2001, which has been identified as the first female 
weblogs in Iranian blogosphere. This study intended to scrutinise the meaning of blogging among the Iranian women bloggers. While it is quite clear from the literature that Iranian women do blogging to seek some kind of "freedom" (Amir-Ebrahimi, 2004, 2008a, 2008b, 2009; Nouraie-Simone, 2005), however, the experiences that they went through and the meanings that they gave to their blogging are still remain unknown.

\section{Methodology}

This study employed Interpretive Phenomenological Analysis (IPA) as a research strategy to explore women bloggers personal experience, and the meaning of blogging as perceived by the bloggers. A qualitative inquiry is the most viable method for this study as it is a pragmatic tool to describe life-worlds 'from the inside out' through participants' own experiences and feelings (Denzin \& Lincoln, 2013; Flick, 2004). For this purpose, the researcher needs to get close to respondents' personal world in order to gain the perspective from 'inside'. IPA attempts to enter the social actors' world to explore their personal world through process of interpretative activity. The process of interpretation will takes place through two steps: in the first step the respondent attempts to make aware of her/his world and at the second step, the researcher will make an attempt to make sense of the respondent's perspective. This is called two-stage interpretation or double hermeneutic (Smith \& Osborn, 2008).

11 women bloggers who lived in Tehran, Iran were selected for this study. They were recruited through the purposive sampling method. "The logic and power of purposeful sampling lies in selecting information-rich cases for study in depth" (Patton, 2002, p.273, Italic in original). Information-rich cases provide a great deal of information relevant to the purpose of inquiry. Studying those cases leads insights and in depth understanding. In a qualitative inquiry with IPA approach, the size of the sampling is usually small. Using IPA approach, sample size will be depending on various factors such as: the degree of applying case study analysis and reporting, the richness of participants' data, and the constraints one is conducting (Smith \& Osborn, 2008).

There were two types of data collected: primary and secondary. The primary data were the information obtained directly from the respondents while the secondary data were information collected from the texts posted by respondents on their blogs. The primary data were collected using in-depth interviews with the respondents. The semi-structured questions were used to guide the interview process in order to acquire necessary information. Semi-structured interview is known as the best tool to collect data for IPA study (Smith \& Osborn, 2008). In semi-structured interview, the researcher tried to make empathy with the respondent. The interviewer will also be allowed to explore new arisen area during interview. While it is not that important to ask questions sequentially, interviewer is allowed to follow participant's concern. In semi-structured interview, instead of following restricted scheduled plan to carry out an interview, an interviewer had to play a role of facilitator and guide (Smith \& Osborn, 2008).

The second source of data was the weblog entries. These data were important for this study in order to acquire an in-depth understanding and knowledge about women blog writing. Besides data obtained from in-depth interviews, weblog entries based on textual data were also applicable for researcher to triangulate the collected data (Flick, 2004). This study intended to analyse three emerging themes: A personal window, pleasure of blogging, and self-therapy.

\section{Findings and discussion}

\subsection{Personal Window}

Blogs are widely heralded as an alternative to mainstream media, as they provide a forum for 'ordinary' people to share their own perspective and experiences with other internet users (Somolu, 2007, p. 478).

Having a space of their own was the main reason why majority of respondents launching their own blogs. Having a blog is viewed as "free from social life barriers". To extend the meaning of the blog, Sima (29) said:

Being as a personal medium, I was encouraged to launch my own weblog to 'say' my ideas. When I came across with 'limitations' in the social sphere, I decided to have my own place to write without being restrained in the virtual world.

When her writings in the journals were censored, she decided to have her own media to convey her own opinion freely. Since Negar (36) discovered personal blog is an "attractive place" in which she can write and quickly express her ideas to the readers, she decided to have her own 'personal window'.

Blogging has given me a personal window to say my words. It is a world, while it is limited, it is my own world. It is the only world which I am the real boss and owner. .. My opinion has never changed 
about weblog. It is my personal window to my world in which I can interact with people around me. Blogging always become an attraction to me.

Unlike the traditional or mainstream media, new media have produced an opportunity for everyone to have their own media to express their own view. (Amir-Ebrahimi, 2008b; Nardi et al., 2004: Somolu, 2007; Stern, 1999) While women did not have any room to channel their opinion, they have employed the blog as "a way of making themselves publicly, expressive and mobile" (Amir-Ebrahimi, 2008b, p. 93); It was a tool "to empower [them] by giving a voice to the unheard" (Somlou, 2007, p. 483).

\subsection{Pleasure of Blogging}

There must be a direct relationship between writing a traditional paper diary in the past and writing a blog in these days. There are people who write. Writing has been associated with their existence. It does not mean that they are good writers or they have a mission to write. No, they have no choice but writing...they write and enjoy the writing. [Negar].persianblog.ir/1390/5/

Almost every respondent, except one, wrote their personal notebooks first before launching their own blogs. Blogging as perceived by Ava (27) is a medium "to practice writing" in order "to find her own style." Respondents like Ana (29) views blogging as an avenue "to prove her writing skill", "to draw audience's attention and feedback", and "to improve her skill and talent" by publishing her entries. In this context, blogging was a platform for women bloggers to practice and improve their writing skill. Like a traditional paper diary, weblog was written by ordinary people about their everyday life, expectations, concerns, wishes and interests. Although, there are some similarities and differences between these bloggers but enjoyment of writing and being able "to pour their heart out" were their main similarities. Unlike diary, having weblog will allow the entries being read by audiences and the bloggers would be able to have communication and interaction and finally self-presentation with the audiences.

While opportunities were very limited for Iranian women to make their presence felt in the public sphere, blogging can be used by women bloggers as a medium to interact with their surrounding environment or social world. This was the only way for Ana to feel the difference as a human being. She said that she started writing since the time when she became familiar with reading. Blog has provided a possibility for Ana to show her skill in writing and to recognize her own ability. For Ana, writing was the most important purpose of blogging. It was the only way that she could feel of being alive. She narrates, "...to feel I am alive, and to feel I am not useless, I have to write, even a short entry".

As a continuation of writing tradition, Bita (32) found that blogging is a digital form of writing. In her view, bloggers like her has started writing long time ago in the forms of diary, story and poem. She views blogging as an unpublished digital work. Bita said "...To be honest, I really believe that blogging is a digital book rather than anything... this is a continuous of tradition of writing and there is no else intention". Emerging weblog has provided a possibility for women to bring their diaries from the personal notebook to the personal weblog (Stern, 1999). Safe and free space, and availability and accessibility for writing and expression, have encouraged women to embrace weblog (Nouraie-Simone, 2005). Meanwhile, there were the same affinity between women and diaries and women and weblog (Herring et al., 2005), Iranian women bloggers shifted their writing's outline from traditional paper diary to modern electronic diary. They moved their diaries from the private to the public sphere.

In the light of personal blog's format and functions, some of the studies considered it a new form of a diary (Herring et al. 2005; Sveningsson Elm, 2009; Stern, 1999; Van Doone et al., 2007). Writing a diary was a very common practice, particularly among women. In fact, it was known as a "traditionally feminine act" (Van Doone et al., 2007). Having been observed their presence and self-expression in public sphere strictly, women have used diaries as a means for self-expression in less- controlled private place (Gannett, 1992). The notebook was a safety means for them to write their expectations, concerns and desires as it was accessible to no one but them. It was being done in the home as it is free and secured place according to them (Svennigsson Elm, 2009).

The most significant difference between a notebook and a blog is that blogs can be read by audiences. The notebook writing was based one's privacy and private space, but a blog was written under the audience observation and disseminated in virtual sphere. Farangis (41) wrote her diary entries in her personal notebook and then her personal computer. When she became familiar with the weblog, she posted online her writings. First she did blogging just for the sake of the enjoyment. Then, she found that she could get an audience feedback on her writings. She was free to write using her own words and her own style without adhering to any grammatical rules. While publishing a paper or a book needs to be strictly following editorial rules in the real world, blogging happened easily through a personal blog of the blogger. 
The blogging could be thought to be a self-reflexive medium for women. In the light of self-reflexivity and personal blog, blogging was a constant narration of bloggers' self to themselves. Blogging also differentiated from traditional paper diary, when it offers an opportunity to bloggers to project themselves to readers. According to Baumeister and Hutton (1987), self-presentation was an effort to deliver some message about oneself or image of oneself to others. Blogging was vehicle for bloggers to share their own perception about them to readers. This was the only available way for them to narrate their own personal stories and to enter the readers' world. As Negar explained:

I have come to the blank pages and have written, and will write permanently. Because, the noises inside my head will only get quiet through writing and only writing. This is the only writing that 'opens hatch' toward people who are unknown to me. Only writing makes my days, from being series of running days, to be a day; to be a time for being. I write. Honestly I have no choice. Just writing tells me my soul is alive and breathes. [Negar].persianblog.ir/1390/7/

\subsection{Self-therapy}

When I am writing more than before, it means I am not feeling well. It means I am dealing with myself to understand what the matter is. So I continue writing. I suppose that if I keep writing, I will get better. I will get lighter. So I keep writing ...[Negar].persianblog.ir/1391/2/

A blog often helped the blogger to pour her heart out through writing. Maral (38) needed to blog as it served her to pour her mind out even if it was not read by audiences.

I need to do bog, even if it is not to be read. In the past years, I had a hidden blog and every day I was writing for myself, without being read by anyone. Now, also I write for myself not for the sake of audience.

Her blog was blocked by government. Yet, she still continued her blogging. Maral never chose to stop blogging, saying that if she is forced to stop blogging, she certainly would find a way to write.

Writing is like a therapy for me. Writing about my life moments is also enjoyable for me. When I am writing, some of my feelings or some of the happenings, as though I am talking loudly about them. This makes me to find out a different sensation about that feeling or that one has happened. Through writing I cross over my mind hurdles.

Maral wrote in an entry that if she did not write she became displeased. She posted: "Writing is such as talking aloud to an invisible audience. You feel there is a somewhere which you are being heard. It makes me calm... Writing, writing regularly in public, makes me better humankind".

Being anonymous in the virtual sphere and writing under the pseudonym has provided opportunity for women bloggers to pour her soul out. Bita viewed blogging as a medium to pour her heart out pseudonymously into the virtual world.

I am writing just for writing to say my words. Because I would like who understand me, show their understanding and show me their supports. I am writing to take a burden from my shoulder, to put it in the fluid river of digital words, and allowed it tumble away beneath the water. Now I will not follow my concerns. I want to be calm. Being calm is what I want to.

For Bita, blogging is a coping strategy to deal with difficulties in communicating with family members and the issues faced in the work place and even the society. She found anonymity is a chance to be expressive and speak out about her private and public issues. A great number of her posts were 'muttering' as she called it. These 'mutterings' were converted to words in the weblog, and "blogging can provide the symptomatic relief of cathartic expression" (Leon Tan, 2008, p. 161).

Forging an author - audience interaction was also seen as a therapy by some respondents. To parya (31), blogging was such a group therapy when someone narrated his/her personal experience and others shared their own opinion. Since no one was known to each other, nobody worried about the other's judgment or situation in the virtual life. When a blogger explained her concerns and grievances, she received a lot of comments as either sympathies or solutions. As the real life, the audience in the virtual life affected the blogger's life on the other side of the screen (Leon Tan, 2008). Sara (24), like her colleagues, gave the same meaning to the blogging too. As a university student, she was enjoying some sort of expressiveness in her university. She was able to join her friends and carry out social activities in her university and public sphere. Changing the social and political climate in Iran directly affected her social presentation. When she came across with the social restrictions and public constraints, she embraced blogging to handle her ongoing loneliness, heartache and isolation. Writing 
acted such a cure for her. Social interaction between a blogger and an audience forged a way to decline tensions. Blogging was a vehicle for bloggers to expose and to express their issues to readers (Leon Tan, 2008).

It was very crucial to bloggers to purge their own thoughts and feeling as it made them to be patient and calm. Pooye (32) said:

When you feel stillness, you encouraged to write your unspoken words which you cannot share with any one. Even if you find somebody, usually you are not sharing the same feeling to share your words, and then you will lose an opportunity to reveal your words or it will be too late. Blogging serves your words 'fresh and hot'.

It also made them to be happy and pleased. It provided dominance for the blogger. Thus, one can deal with one's tensions and frustrations. According to Yas (27):

Writing has always been an inseparable part of my life. I am blogging for myself and then for whom they understand me. I enjoy writing. By writing I pour my concerns out. It gives me dominance and this is pleasurable.

While Yas faced a variety of problems in her private as well as social life, blogging helped her vent her feelings and keep them away from her mind. Though she called her blog a 'blurred mirror' because of its inability in being expressive, blogging enabled her to share her concerns with the audience. Blogging provided a space for her to demonstrate her relationship with family members like husband and her mother-in-law. When she had problems in her marital life and found no one to support her in her real life, blogging served her to highlight most of the issues in details. In short, blogging enabled her to cope with the vicissitudes of her post divorced life.

There have been substantial studies (Baikie \& Mcllwain, 2008; Leon Tan, 2008; Lepore \& Smyth, 2002; Nagel and Anthony, 2009; Pennebaker, $1997 \&$ 2002) that considers writing as a redress. They have emphasised on the importance of expressive writing as a traditional psychotherapy-catharsis and self-therapy. Meanwhile, a number of studies (Garcia-Gomez, 2009; Leon Tan, 2008; Nagel \& Anthony, 2009) have assumed blogging primary function such as traditional paper diaries and journals. Nagel and Anthony (2009) pointed out that "as with many textual writing interventions, blogging can be beneficial" (p. 42). A survey conducted in the United States showed that almost $50 \%$ of bloggers used their blogging as a form of self-therapy (Leon Tan, 2008). Bloggers used the weblog as a tool to deal with their stress, tension, anxiety, frustration and concerns when they were not able to speak their mind. It was a means of catharsis for bloggers. The format and function of a blog permitted a blogger to review her posts over time. " In reviewing a blog, a writer is able to observe, over time, this growing voice, its tendencies, its tones, its complaining and celebrating" (Leon Tan, 2008, p. 151).

\section{Conclusion}

The discussion above revealed that women bloggers have given different meanings to blogging. Before embarking into blogging, almost all of them have had an experience writing in their traditional paper diaries. Majority of bloggers employed blogging to think through writing (Nardi et al., 2004), to purge their minds from stress and worries. Personal window was an opportunity provided by blog for respondents to say whatever they would like while they feel free of social world's restriction. It gave a voice to bloggers to speak up their opinions and a chance to be heard. While for centuries, women used diaries to say in words what they could not say aloud (Thompson, 1994), blog was a free space for women bloggers to perceive how to convey their meanings through writings, and a 'safe house' to speak freely for the first time (Leon Tan, 2008).

\section{References}

Amir-Ebrahimi, M. (2004). Performance in everyday life and the rediscovery of the "Self" in Iranian weblogs. Bad Jens 7 (September). Retrieved from: http://badjens.com/rediscovery

Amir-Ebrahimi, M. (2008a). Blogging from Qom, behind walls and veils. Comparative Studies of South Asia Africa and the Middle East, 28(2), 235- 249. http://dx.doi.org/10.1215/1089201x-2008-002

Amir-Ebrahimi, M. (2008b). Transgression in narration: The lives of Iranian women in cyberspace. Journal of Middle East Women's Studies, 4(3), 89-118. http://dx.doi.org/10.1353/jmw.0.0021

Amir-Ebrahimi, M. (2009). Weblogistan: The emergence of a new public sphere in Iran. In S. Seteney (Ed.), Publics, Politics and Participation: Locating the Public Sphere in the Middle East and North Africa. NY: Social Science Research Council.

Baikie, K. A., \& Macllwain, D. (2008). Who does expressive writing work for? Examination of alexithymia, splitting, and repressive coping style as moderators of the expressive writing paradigm. British Journal of Health Psychology, 13(1), 61-66. http://dx.doi.org/10.1348/135910707X250893 
Baumeister, F., \& Hutton, G. (1987). Self-presentation theory: Self-construction and audience pleasing. In B. Mullen, \& G. Geothals (Eds.), Theories of group behavior. NY: Springer.

Denzin, N., \& Lincoln, Y. (2013). The discipline and practice of qualitative research. In N. Denzin, \& Y. Lincoln (Eds.), Collecting and Interpreting Qualitative Materials (4th ed.). Thousand Oaks, CA: Sage.

Doostdar, A. (2004). "The vulgar spirit of blogging": On language, culture, and power in Persian Weblogestan. American Anthropologist, 106(4), 651-662. http://dx.doi.org/10.1525/aa.2004.106.4.651

Flick, U. (2004). Triangulation in qualitative research. In U. Flick, E. Kardorff, \& I. Steink (Eds.), A companion to qualitative research. London:Sage.

Flick, U. (2009). An introduction to qualitative research. London: Sage.

Gannett, C. (1992). Gender and the journal: Diaries and academic discourse. State University of New York: Albany.

Garcia-Gomez, A. (2009). Teenage girls' personal weblog writing. Information Communication Society, 12(5), 611-638. http://dx.doi.org/10.1080/13691180802266657

Halevi, J. (2006). The Iranian Weblog Research Project: Survey Results (Unpublished Master dissertation). http://www.persianimpediment.org/research/iwrpresults.pdf

Hendelman-Baavur, L. (2007). Promises and perils of Weblogistan: Online personal journals and the Islamic Republic of Iran. The Middle East Review of International Affairs, 11(2), 77-93.

Herring, S., Kouper, I., Paolillo, J., Scheidt, L., Tyworth, M., Welsch, P., \& Yu, N. (2005, January). Conversations in the blogosphere: An analysis. In System Sciences. HICSS'05. Proceedings of the 38th Annual Hawaii International Conference on IEEE. Big Island, Hawaii.

Kelly, J., \& Etling, B. (2008). Mapping Iran's online public: Politics and culture in the Persian blogosphere. Berkman Center. Retrieved from http://cyber.law.harvard.edu/publications/2008/Mapping_Irans_Online_ Public

Lepore, S., \& Smyth, J. (2002). The writing cure: How expressive writing promotes health and emotional well-being. Washington, DC: American Psychological Association.

Leon Tan, M. (2008). Psychotherapy 2.0s My Space ${ }^{\circledR}$ blogging as self-therapy. American journal of psychotherapy, 62(2), 143.

Nagel, D., \& Anthony, K. (2009). Writing therapy using new technologies: The art of blogging. Journal of poetry therapy, 22(1), 41-45. http://dx.doi.org/10.1080/08893670802708001

Nardi, B., Schiano, D., \& Gumbrecht, M. (2004, November). Blogging as social activity, or, would you let 900 million people read your diary? In Proceedings of the 2004 ACM conference on Computer supported cooperative work. NY: ACM.

Nouraie-Simone, F. (2005). Wings of freedom: Iranian women, identity and cyberspace. In F. Nouraie-Simone (Ed.), On shifting ground: Muslim women in the global era. NY: City University of New York

Patton, M. Q. (2002). Two decades of developments in qualitative inquiry a personal, experiential perspective. Qualitative Social Work, 1(3), 261-283. http://dx.doi.org/10.1177/1473325002001003636

Pennebaker, J. (1997). Writing about emotional experiences as a therapeutic process. Psychological Science, 8(3), 162-166. http://dx.doi.org/10.1111/j.1467-9280.1997.tb00403.x

Pennebaker, J. (2002). Writing, social processes, and psychotherapy: From past to future. In S. J. Lepore, \& J. M. Smyth (Eds.), The writing cure: How expressive writing influences health and well-being. Washington, DC: American Psychological Association.

Sifry, D. (2007) The State of live Web, April 2007, Sifry's Alerts. Retrieved from http://www.sifry.com/alerts/ archives/000493.html

Smith, J., \& Osborn, M. (2008). Interpretative phenomenological analysis. In J. Smith (Ed.). Qualitative psychology: A practical guide to research methods (2nd ed.). CA: Thousand Oaks.

Somolu, O. (2007). 'Telling our own stories': African women blogging for social change. Gender \& Development, 15(3), 477-489. http://dx.doi.org/10.1080/13552070701630640

Sreberny, A., \& Khiabany, G. (2010). Blogistan: The internet and politics in Iran. London: IB Tauris.

Stern, S. (1999). Adolescent girls expression on web home pages: Spirited, sombre and self-conscious sites. 
Convergence: The International Journal of Research into New Media Technologies, 5(4), 22-41.

Sveningsson Elm, M. (2009). Exploring and negotiating femininity: Young women's creation of style in a Swedish Internet community. Young, 17(3), 241-264. http://dx.doi.org/10.1177/110330880901700302

Thompson, J. (1994). Social theory and the media. In D. Crowley, \& D. Mitchell (Eds), Communication Theory Today. Cambridge: Polity.

Van Doorn, N., Van Zoonen, L., \& Wyatt, S. (2007). Writing from experience: Presentations of gender identity on weblogs. European Journal of Women's Studies, 14(2), 143-158. http://dx.doi.org/10.1177/ 1350506807075819

\section{Notes}

Note 1. Internet world stats: usage and population statistics, June 30, 2012. Retrieved from http://www.internetworldstats.com

Note 2. Blogs statistics, Nov 11, 2011. Retrieved from http://www.blogpulse.com

\section{Copyrights}

Copyright for this article is retained by the author(s), with first publication rights granted to the journal.

This is an open-access article distributed under the terms and conditions of the Creative Commons Attribution license (http://creativecommons.org/licenses/by/3.0/). 